Research Article

\title{
The Challenges Faced by Undergraduate Women during the COVID-19 Pandemic in Saudi Arabia
}

\author{
Amal Al-Rasheed (iD \\ Information Systems Department, College of Computer and Information Sciences, \\ Princess Nourah Bint Abdulrahman University, Riyadh, Saudi Arabia \\ Correspondence should be addressed to Amal Al-Rasheed; aaalrasheed@pnu.edu.sa
}

Received 9 July 2020; Accepted 18 June 2021; Published 28 June 2021

Academic Editor: Enrique Palou

Copyright (C) 2021 Amal Al-Rasheed. This is an open access article distributed under the Creative Commons Attribution License, which permits unrestricted use, distribution, and reproduction in any medium, provided the original work is properly cited.

The latest COVID-19 pandemic is a specific and unusual event. It forced universities to close their doors and move fully to distance education. The sudden shift from traditional education to full distance education created many challenges and difficulties for universities, faculty members, and students. This study aims to investigate the challenges and obstacles faced by undergraduate women in Saudi Arabia universities while using online-only learning during the COVID-19 pandemic outbreak. Moreover, this study provides some recommendations to address these challenges from undergraduate women's perspectives. The study used a qualitative research methodology to investigate the challenges and difficulties. The participants were undergraduate women selected using random purposive sampling technique from the population of College of Computer and Information Sciences (CCIS) at Princess Nourah Bint Abdulrahman University (PNU), Riyadh, Saudi Arabia. The final sample consisted of 68 undergraduate women who responded to a predesigned open-ended questionnaire that was sent via e-mail to targeted respondents. The data gathered from the questionnaire were analyzed using qualitative content analysis. Results of the research revealed that the most obvious challenges identified by the participants were technical issues, lack of in-person interaction, distractions and time management, lack of a systematic schedule, stress and psychological pressure, missing the traditional university environment, limited availability of digital devices, and lack of access to external learning resources.

\section{Introduction}

The coronavirus disease (COVID-19) first originated in Wuhan, China, at the end of December 2019 [1]. The initial COVID-19 outbreak in Wuhan spread rapidly and affected other parts of China. On January 23, 2020, Wuhan authorities took unprecedented action and locked down the city to reduce the possibility of further transmission of the disease [2]. The same measures were later taken elsewhere in China. However, COVID-19 cases were detected in several other countries within a few weeks, and it soon became a global threat [3]. The World Health Organization subsequently declared the COVID-19 epidemic as a pandemic.

In response to COVID-19, public health experts and government officials in several countries adopted various restrictions to prevent the spread of the pandemic, including quarantine, social distancing, working from home, and strengthening health facilities [4]. In many countries, attempts to reduce the spread of the coronavirus among populations led to the widespread closure of various educational institutions, such as schools, colleges, and universities.

By the end of March 2020, 150 countries had closed educational institutions nationally, affecting more than $80 \%$ of the student population worldwide. Campus events, such as workshops, conferences, sports, and other activities, were either postponed or cancelled by most universities around the world. Universities also rapidly shifted from the face-toface delivery mode of different courses and programs to the online delivery mode [5]. This put pressure on undergraduates and created many challenges and difficulties [6]. Support was required from universities, including the development of formal training on software and communities through which students share information. However, 
COVID-19 caused, and to some degree is still causing, considerable stress, uncertainty, and extra work for undergraduates.

Undergraduate women who exhibit family responsibilities may be particularly vulnerable to challenges more than their men counterparts [7]. There is no doubt that women are probably taking on more responsibilities than men when they become accountable for caring of elderly, ill family members, and siblings who are out of school [8]. Due to the disease outbreak, burden of these responsibilities increased even more, as nurseries were closed, hospitalization was rationed, and help in household affairs could not be found. These responsibilities pose major challenges to undergraduate women and limit their ability to continue their education effectively. The current pandemic may further worsen already existing problems. The timeline of the pandemic is uncertain, further affecting undergraduate women's education achievement, lives, and physiological health. Shedding light on these challenges helps in addressing them and provides more support for undergraduate women [9].

A large body of literature exists on the impact of closing educational institutions to reduce the spread of the COVID19 pandemic in the community [10-15]. While many studies investigated the various effects of the pandemic outbreak on higher education in general $[5,16,17]$, few publications addressed some issues regarding undergraduate students $[18,19]$. To the best of the researcher's knowledge, no study has investigated the actual challenges that undergraduate women faced during the pandemic outbreak. In the present study, the author will investigate the challenges and difficulties faced by undergraduate women in Saudi universities due to the sudden shift from traditional education to distance learning.

The remainder of this article is structured as follows. Section 2 provides brief background information on how PNU has responded to COVID-19. Section 3 highlights the purpose and significance of this study. Section 4 describes the methodology of the research, including the treatment sample, sampling technique, survey instrument, data collection, and data analysis. In Section 5, the research results were discussed. Section 6 gives a brief discussion on the results given in Section 5. Section 7 presents the conclusion and includes some suggestions for further research.

\section{How Is PNU Responding to COVID-19?}

On March 8, 2020, Saudi Arabia's Ministry of Education announced the closure of schools and universities in response to the "preventive and precautionary" measures recommended by the Ministry of Health to protect students and staff. The decision covered all educational institutions, including schools, universities, and institutions for technical and vocational training. The Ministry of Education guided the activation of virtual schools and distance education when the schools closed to ensure that the educational process continued in an effective and quality manner [20].

Because of the well-established IT infrastructure in Saudi's higher education institutions, they were able to shift to distance learning within a day of suspension of schools and universities. All remote teaching was delivered via Learning Management Systems (LMS), with some synchronous sessions being delivered, at the behest of faculty members outside of these platforms (e.g., Zoom and Google Meet). To ensure access to all, universities and colleges provided laptops and Internet access to some disadvantaged students [21].

PNU is a university for women in Saudi Arabia and the biggest university exclusive to women in the world. In response to the instructions from the Ministry of Education, the university moved to online education and a remote work paradigm. PNU has adopted Blackboard as the primary learning management system (LMS) for online courses. Blackboard offers a simple interface for uploading course content, gathering students' assignments, running tests and exams, communicating with students, and evaluating students' work.

The Department of E-learning at PNU worked on preparing and implementing an integrated emergency plan aimed at transforming regular education into full-fledged distance education through four stages: preparation for systems, preparation for faculty and students, implementation, and impact measurement. In this regard, the department published manuals and guidelines for all users, in addition to carrying out a set of remote training workshops for faculty members, including basic skills for using the Blackboard platform, setting up virtual classes, recording lectures, and doing educational design. Meanwhile, the Department of Information and Communications Technology at PNU raised the capacity of the system by more than threefold and provided alternative solutions for concurrent classes and electronic tests. Consequently, students can complete the educational process by using Blackboard, which enables them to attend virtual classes and perform assignments, projects, tests, and exams. Technical support was provided to all users 24 hours a day through a set of channels [22].

An indication of the magnitude of the efforts done by PNU during quarantine is given by statistics reported by the Department of E-learning: PNU, with a population of approximately 38,986 students, accredited the management of an estimated 6,395 virtual classes during a six-week period. In addition, about 118,167 exams were conducted for 5,602 courses, 7,308 engaging webinars were held for online events, and approximately 116 scientific theses were discussed online during that time [23].

\section{Purpose and Significance of the Study}

Generally, students all over the world are facing many challenges due to pandemic outbreak. The focus of this research is on the challenges faced by undergraduate women. There is no doubt that undergraduate women are probably taking on more responsibilities than their men counterparts [7], especially when they carry the responsibility of caring for elderly and ill family members, as well as for siblings who are out of school [8]. Due to the pandemic outbreak, the burden of these responsibilities increased even more, posing major challenges and difficulties to 
undergraduate women and limiting their ability to continue their education effectively. In this study, shedding light on the challenges facing undergraduate women due to quarantine and distance learning helps in addressing these challenges and provides various types of support for undergraduate women. Moreover, this study contributes to the research of emergency teaching and crisis management. The study also gives the universities a clear picture of the real situation of online learning during suspension from the undergraduate women's perspective, especially with the lack of previous references to similar crises [9].

\section{Methodology}

4.1. Study Design. This study was conducted with a qualitative approach. Qualitative research has been used in numerous academic disciplines to achieve deeper understanding of issues related to the target organization [24]. The qualitative approach was used in this study because of its suitability in gathering initial knowledge and exploring the understudied phenomena [25] as there has been no study in the literature reported yet on the challenges faced by undergraduate women during COVID-19, particularly in Saudi Arabia.

4.2. Setting and Participants. This study took place in CCIS at PNU, located in the capital of Saudi Arabia. This research was conducted from April to May 2020 (during quarantine). The population of the students at CCIS was approximately 3,800 . In total, 68 undergraduate women responded and completed the questionnaire. The demographic profile of the respondents is as follows: Regarding gender, all the participants were females. Regarding marital status, sixty participants were single and eight participants were married. Overall, the sample included 63 participants aged between 20 and 24 years, with five aged 25 years or older. The participants were studying a variety of different majors at CCIS (Computer Science, Information Systems, and Information Technology).

4.3. Sampling Technique. A random purposive sampling technique was used for this study, as it is suited for qualitative research when the purposive sample is larger than that a researcher can handle. The researcher chose cases at random from the sampling frame consisting of a purposefully selected sample [26]. In the context of this study, the researcher first obtained a list of individuals of interest using purposive sampling. Individuals of interest for this study were full-time undergraduate women at CCIS. Then, the researcher selected a random sample of 150 institution e-mail addresses from the list. According to Miles and Huberman [27], random purposeful sampling "adds credibility to sample when potential purposeful sample is too large." The random purposive sampling technique enabled the researcher to target and select undergraduate women who have experienced online-only instruction during the pandemic outbreak in a Saudi university and possess sufficient insights on the challenges encountered and how to resolve them.

4.4. Survey Instrument. To collect data, the research utilized a questionnaire aimed at assessing the challenges and difficulties faced by undergraduate women during the COVID19 outbreak. All the questions of the questionnaire were open-ended to give the respondents the freedom to answer in as much detail as they like and to enable the researcher to qualify and clarify their responses. The questionnaire consisted of four sections. The first section asked about some demographic information. The second was concerned with technical and personal challenges and difficulties that the students face during online-only instruction due to the COVID-19 pandemic. The third section asked the students to mention their technical and personal recommendations and requirements for addressing these challenges. The fourth aimed to explore the factors that helped the students to study online due to the COVID-19 outbreak. The questionnaire was adjusted in terms of validity and reliability. The Arabic version, students' mother tongue, of the questionnaire was implemented to make it easier for students to complete it, as the students' responses would not be affected by their misunderstanding of some words or statements.

4.5. Data Collection. The data were collected by handling an open-ended, structured questionnaire. The researcher contacted 150 students via e-mail and asked them to participate voluntarily in this study. Seventy-seven students agreed to participate; hence, the questionnaire was sent to them via e-mail. All respondents were assured that their individual responses were confidential. Students were asked in the questionnaire for additional contact information in case they can engage in a conference call. All the questions were marked as required, and participants were recontacted to fill in missing questions. Nine students were excluded because they did not respond to the questionnaire. In total, sixtyeight participants responded and filled out the questionnaires ( $45.34 \%$ of all respondents). This number is considered adequate for the qualitative study as it encompassed the views of participants and, most importantly, allowed the present study to reach its saturation point of data [28].

4.6. Data Analysis. After translating the collected data into English and reading the transcripts closely, the qualitative content analyzing process was applied in an organized manner through segmenting, inductive coding, and developing category systems. Segments containing meaning units were defined, and a label for each category was created, after which segments or codes were assigned to the appropriate categories. To define the relationships in the coding, the process of continuously comparing data segments into coding themes was applied carefully. The process of emerging and condensing yielded 57 codes, which were divided into subcategories and categories based on their similarities. Two faculty members double-checked the 
study's preliminary findings to make sure they were reliable. Under their supervision, the researcher read the transcripts many times to ensure that the findings were accurate and free of bias.

4.7. Ethics. An ethics approval was obtained for this study from the PNU Institutional Review Board (Approval Number: IRB: 20-0157).

\section{Results}

This section presents the most important results of the two parts of the survey. The first part concerned challenges experienced by respondents during quarantine. The second part gathered students' recommendations for addressing the challenges.

\subsection{What Challenges and Difficulties Did You Face during} Online-Only Instruction due to the COVID-19 Pandemic? An analysis of the results reveals several components perceived by undergraduate women as their obstacles and challenges in online-only learning during quarantine. Table 1 lists the main perceived challenges and their percentages.

5.1.1. Technical Issues. The biggest challenge reported by study participants was technical issues (87\%). Most participants had technology-related issues that prevented them from participating actively in synchronous online learning. Overall, our analysis suggests four technology-related issues. First and foremost is Internet connectivity. It is a fact that networks were unable to cope with the extra load they suddenly faced and broadband speeds slowed down due to the sheer volume of people using the Internet [29]. Many students reported that their audio and video were cut off during synchronous lectures because of fluctuations of the Internet, which hindered their focus and follow-up with the instructor. Loading asynchronous lectures was another challenge because it took a long time. Slow or interrupted Internet service was a constant concern for students, who feared sudden interruptions while taking online tests or doing presentations. The second technical issue that students faced is related to Blackboard. Most students encountered difficulties signing into the learning platform and accessing lectures and were unable to understand their teachers or upload assignments. Furthermore, Blackboard had a suspension of service due to maintenance purposes. The third issue is technostress and adapting to unfamiliar technology. Although the students in the research are accustomed to using technology and online learning, the sudden shift to online-only learning for several months forced the students to use excessive technology that they had not used or heard of before. The last issue is the difficulty of computer maintenance. Because of the quarantine, it was very difficult for students to obtain maintenance for their devices, especially for the microphones and headsets they needed extensively during that period.
5.1.2. Lack of In-Person Interaction (Instructor-Student/ Student-Student). Several challenges related to the lack of in-person interaction were identified in this study. A total of $85 \%$ of the participants found it difficult to continue learning in the face of digital learning and the lack of face-to-face interaction with their instructors and classmates. They faced more obstacles with online learning compared to traditional learning because they missed having in-class discussions, asking questions, and getting instant feedback from their instructors. Difficulty in understanding the content, especially for classes better adapted for the face-to-face format, was another challenge the learners reported. This was a serious problem in particular for students who attended hands-on classes, such as labs, as they needed instructors to be in the same physical environment. Students felt anxious and lost because they had concerns about their learning and needed a response. Teamwork is another challenge that students faced during quarantine. Many students expressed the difficulty of staying connected and working together. Agreeing on meeting times was a big challenge as the traditional 8:30 am-5:00 pm schedule did not work for the entire team given the members' different timetables and family-related duties. Discussions, brainstorming, and allocating tasks for team members were also difficult in virtual meetings. In addition, participants reported the lack of instructors' availability as a challenge because the delays in getting responses back from their instructors affected their study. This was particularly evident in asynchronous online discussions when students had to wait until others had read and responded to their posts or e-mails [30].

\subsubsection{Distractions and Time Management. Distractions and} time management were a challenge for $68 \%$ of students in this research. For some students, online learning can be more convenient than traditional on-campus options. However, concentrating can be difficult. Studying at home or wherever students may be meaning more distractions and interruptions than normal may occur, particularly when family and probably younger siblings are around. Time management is more difficult because of such challenges and the additional obligations that undergraduate women may be given at home. Female students with children faced additional challenges during quarantine due to the closure of nurseries, which made it difficult for them to balance their duties toward their children and the time allocated to learning. Another issue reported by many students was that the required time allocated to learning in an online environment was far more than the time required in traditional face-to-face learning [31]. The students in this study emphasized that the online environment simply entailed more time than a face-to-face class to effectively accomplish just about anything.

5.1.4. Lack of a Systematic Schedule. One of the new challenges that students faced during the sudden shift to full distance education was the absence of a systematic schedule, with a total of $57 \%$ of the students reporting this as a major difficulty. The students' daily routine became entirely different from a 
TABLE 1: Views of respondents about the challenges and difficulties of online-only instruction during quarantine.

\begin{tabular}{lc}
\hline Challenges & No. of respondents (\%) \\
\hline Technical issues & $59(87)$ \\
Lack of in-person interaction (instructor-student/student-student) & $58(85)$ \\
Distractions and time management & $46(68)$ \\
Lack of systematic schedule & $39(57)$ \\
Stress and psychological pressure & $35(51)$ \\
Missing traditional university environment & $26(38)$ \\
Limited availability of digital devices & $14(21)$ \\
Lack of access to external learning resources & $8(12)$ \\
\hline
\end{tabular}

Number of respondents: $N=68$.

typical day prior to the quarantine. Before, they would dedicate their morning and afternoon hours to study at the university and the rest of the day to do their coursework at home, but the quarantine turned this schedule upside down. The students severely missed the systematic schedule, as lectures and exams were held at varying times of the day (or even night). They were also overwhelmed by the numerous announcements and alerts, some of which were posted at night. To continue their studies, the students became attached to their devices throughout the day and were afraid that they would miss something. The instructors were also affected by this sudden shift, and since they were under pressure to complete the educational process, they missed organizing and scheduling requirements for students that sometimes students receive more than one lecture or tests at the same time.

5.1.5. Stress and Psychological Pressure. The new critical situation created mixed feelings of anxiety, stress, fear, and psychological pressure in people [32]. One of the major challenges reported by the study participants was feeling stress and psychological pressure (51\%). This study found that this challenge has three faces. The first is stress and anxiety. It is to be expected that students will feel stressed under the current circumstances. The study participants expressed their constant concern about the Internet outage and, consequently, their inability to submit assignments or complete exams. They also expressed fears around distance learning, grades, tests, and deadlines. The second is psychological pressure. In general, an emergency situation fuels psychological pressure, but everyone feels the effects differently. Most students experienced a great deal of pressure due to the many study requirements and the submission times. Moreover, they reported an overload of classwork that they would not have had in regular circumstances. The third is the uncertainty of the future. The sudden switch to online classes caused anxiety among participants and raised questions about their academic futures. Some have considered taking off the current semester if, for example, the university continued to stick to online instruction, while others are worried about their inability to complete field training during quarantine, which would delay their graduation. There, too, were others who feared an outbreak and their unknown fate.

5.1.6. Missing the Traditional University Environment. While some students found distance learning to be convenient, $38 \%$ reported missing the traditional university environment. They missed meeting people and interacting with their peers, students, and supervisors. The university can switch from face-to-face learning to online learning at any time, but real-life experiences on campus cannot be virtual. Nevertheless, there are likely limitations as to how far the digital switch can go in the longer term. While a university can be effective in conducting its online education, there does not seem to be any reasonable virtual substitute for field trips or sporting events or the social and cultural attractions of campus life [33]. Generally, students value campus life very much, but they found no alternative during quarantine.

5.1.7. Limited Availability of Digital Devices. It is understood that online learning does not take place without a computer and an Internet connection [34]. Lack of digital devices is a challenge for $21 \%$ of the study participants. Some students faced the huge challenge of not even having a computer at home due to financial constraints. In regular circumstances, these students rely on computer labs and facilities available at the university. Other students reported that having outdated computers hindered the regular continuation of their study. Even for some students who did not have financial constraints, the rapid transition to online learning was also challenging because they had to share their computers with their family members, which meant reduced study time.

5.1.8. Lack of Access to External Learning Resources. Some participants (12\%) reported that they were unable to get some required learning resources, for instance, borrowing books from the library, which hindered their ability to complete some assignments and projects. The closure of university libraries undoubtedly had a negative impact on learning, as the students, in addition to borrowing books, frequently met in the study halls to discuss their joint assignments and projects. Moreover, the quarantine prevented students from completing their field training, which could only be done by going to the training places.

5.2. What Are Your Recommendations for Addressing These Challenges and Difficulties? Most of the recommendations suggested by the participants seem to have emerged in response to the challenges described above. The possible strategies the respondents recommended to address the 
challenges during online-only instruction due to the COVID-19 pandemic are presented as follows.

5.2.1. Provide Training and User Manuals. The university should provide students with comprehensive training and user manuals that can be consulted as detailed references to effectively support their use of the online learning platform (Blackboard).

5.2.2. Interactive Virtual Learning. Make the online learning process interactive and accompany it with visual and auditory effects to make the rigid educational process more attractive and interesting. In addition, use more effective methods for teaching practical subjects. For instance, a special electronic whiteboard application can be used in which all tools (e.g., pens, engineering tools, and tables) are included.

5.2.3. Upgrade the Technical Infrastructure of the University. Improve the capacity of the servers and regularly maintain the online learning platform (Blackboard) to make the online aspect a core of teaching and learning.

5.2.4. Avoid Rigid Exam Instructions. Students request for flexible measures in their examinations because they are concerned that the outbreak will adversely affect their examination performance. In this regard, students provided many recommendations, such as getting clear directions regarding their exams, assignments, and projects; greater availability of faculty members during exam time to respond to students' queries; the ability to resume an exam later if the student cannot complete one because of technical problems; the advantage of using various devices to take an exam; changing the assessment types to fit the online mode.

5.2.5. Address the Lack of Equipment or Connectivity. The provision of devices and Internet access to students in need and services and applications for cell phones should be made a priority. Universities should collaborate with leading computer manufacturers and suppliers and find affordable options for students to purchase computers and laptops.

5.2.6. Use Various Modes of Teaching. While faculty members have the opportunity to either prerecord lectures or conduct live lectures, students prefer to have both alternatives simultaneously. On the one hand, some students prefer live lectures as these enable them to interact with their instructors and colleagues. On the other hand, some students prefer to receive recorded lectures because they may have to take care of some family members or share technology devices with others. Accordingly, they cannot be restricted by time limits.

5.2.7. Provide Systematic Schedule. A systematic schedule for lectures and tests must be provided similar to what happens with traditional learning, and both faculty members and students should adhere to it.

5.2.8. Offer Virtual Office Hours. Faculty members should stay in touch with students by holding their meetings at a regular time or a time most convenient for them via meeting platforms, which enable multiple people to join over the course of the meeting.

5.2.9. Build a Communication Platform. A new platform must be developed to provide a convenient way of communication and announce lecture schedules, test times, assignments, and projects. This platform can be a reference for faculty members and students.

\section{Discussion}

This study focused on the perceptions of undergraduate women regarding the obstacles and challenges in learning remotely during quarantine. It is not overly surprising that some challenges identified by the participants are similar to general issues related to online learning identified in previous research. However, new challenges and difficulties have arisen due to the quarantine and the pandemic outbreak. Figure 1 illustrates the main challenges faced by undergraduate women during quarantine.

Technical issues associated with the use of technology in learning have long created challenges [35]. To be fair, it is one thing for universities to have the necessary technological and technical infrastructure to support virtual courses for a relatively significant percentage of undergraduates. It is quite another, and considerably different, way to provide the technical and technological needs for generally all courses for all students in a timeframe that, in many cases, has been less than a week. However, from the beginning of a crisis, universities must try to mitigate the problems as much as possible. This may be accomplished in various ways, including providing students with alternatives in case of Internet connectivity issues, such as recording lectures and offering the option to resume interrupted exams and other tasks [36]. It is also equally important to provide students with comprehensive training on using Blackboard and guides and manuals for use as reference. Moreover, universities should pay attention to the digital inequities issue, which has been exacerbated after the shutdown of physical university buildings. Given that faculty members were not given sufficient time to prepare for remote teaching, they were challenged to find creative and innovative solutions to resume teaching [37]. However, the excessive use of new technology causes technostress and distraction for students. Therefore, it is recommended that faculty members agree on using few technologies and directing students with videos and tutorials to support thezm in using these technologies. Another important factor in facing technical problems is helping students understand from the beginning of the crisis that problems are going to occur. This understanding will help them ease their own stress by recognizing that the 


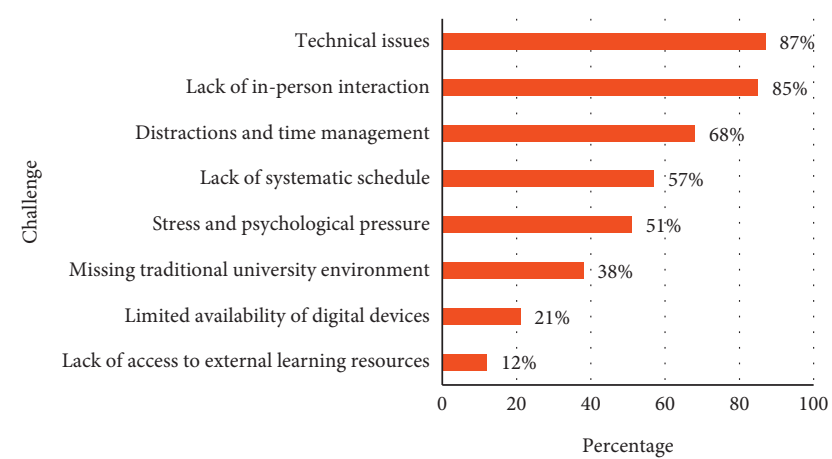

FIgURE 1: The main challenges faced by undergraduate women during quarantine.

situation is the new normal and, accordingly, make backup plans to facilitate their work [38, 39].

Another issue that was highlighted in this study is related to the lack of in-person interaction with both instructors and classmates. In reality, an inherent learning structure exists on campus, harmony and tangibility that keep students linked to the academic community [40-42]. Many learners adapt easily to a virtual environment. Some just cannot. Now students who used to learn one way need to adapt quickly. Students in traditional university settings were shocked by the hard reality that much of their work requires social interaction. They found that having a face-to-face meeting with their instructors is indispensable, especially in some courses like graduation projects [43]. In addition, moving to full online instruction can be especially difficult for students taking practical classes that are better suited to face-to-face learning, such as courses with laboratory components $[40,44]$. Research indicates that undergraduates who are academically marginal struggle more with full online instruction [45]. Fortunately, the widespread use of computer technologies in education has reshaped the role of faculty members, who are encouraged to innovate interactive forms of technology-based instruction that foster collaboration and participation $[41,46]$. Faculty members should provide an interactive learning environment designed to attract and inspire students to share their thoughts and experiences. They should also take advantage of various computer technologies. Although not suitable for all learners, videoconferencing programs such as Skype, Zoom, or FaceTime may be good alternatives for direct face-to-face interaction. Moreover, text and phone communications can replace the benefits of in-person contact to a point.

Distractions and time management were another challenge identified by undergraduate women. More distractions than usual may actually accompany online learning during quarantine, particularly when all family members are at home day and night. Time management becomes more challenging due to distractions and possibly additional responsibilities. This study is consistent with previous research on the importance of applying time management strategies to assist in the online learning process $[33,35,38]$, such as having a schedule and setting a time to do online work. These strategies can influence the success of the online learning process [38, 47]. Suggestions for maintaining the workload include creating a study schedule, using calendars and reminders, taking advantage of productivity applications, avoiding distractions, establishing realistic personal expectations, and dividing tasks, and setting deadlines among group members. Students should always seek to find a quiet time and place in their home to complete their coursework, even if that time is late at night.

A new challenge raised during this crisis and documented by a number of the participants was losing a systematic schedule. Online learning is not new to universities, as many courses are taught remotely, but teaching all courses to all students completely online at once is a new situation [48]. Without a doubt, this exceptional situation confused universities, instructors, and students [49]. The sudden and complete transition to remote teaching increased the load on the servers, which made it difficult to deliver all lectures according to the regular schedule. To address this, the study schedule was extended throughout the day to relieve the heavy server load, which in turn burdened the students who were used to a regular schedule. In addition, some instructors were forced to give exams late or at the end of the week to ensure that all students could get access to the learning platform. The crisis also pushed university faculty members to shorten their academic courses for the semester and suspend or cancel assignments and projects, further increasing the confusion of students. To resolve this issue, academic departments in the colleges have to do their part in organizing schedules that suit the new situation and the conditions of the instructors and students. Instructors also have an important role in communication and organization in terms of scheduling assignments, tests, and other tasks required from students.

The issues of stress and psychological pressure are referred to as a challenge by a high proportion of the participants. Anxiety, stress, fear, and pressure are features of the current uncertain times [50]. The present study is consistent with previous research in marking stress and psychological pressure as issues that accompany online learning due to the COVID-19 outbreak. In [15], Buzkurt and Sharma raised an important question: "in a time of crisis, when people are under trauma, stress and psychological pressure, should we focus on teaching educational content or should we focus on teaching how to share, collaborate and support?" According to Bozkurt and Sharma, a crisis is the time to abandon our fixation with utilizing cool, shiny technology to teach, convey knowledge, and deliver lectures. We should realize that people will not remember the presented educational content when things return to normal, but they will remember how they felt, how we cared for them, and how we supported them $[15,51]$. We should abandon the concept that what is taking place is a fantastic online learning experiment and a chance to try out new online pedagogical approaches. Instead, we should strive to increase our emotional presence in order to foster empathy and care and then focus on several sorts of presence, such as teaching, cognitive, and social presence [52]. Equal to teaching, universities should also build support communities and encourage faculty members to share the knowledge and experience they have to provide efficient and 
meaningful learning processes [53]. These methods should be geared toward treatment, empathy, and caring rather than just learning. Faculty members should show their commitment to support their students and institute teaching and learning on the grounds of a pedagogy of care, not on purely didactic and insensitive grounds $[15,54]$.

The closure of university campuses and the concomitant abolition of all sporting and sociocultural activities likewise created a new challenge for undergraduate women. Students left behind more than just their classes and academics. They miss important spaces where they meet and talk about their nonacademic interests and miss various sporting and sociocultural activities. Overall, they miss the traditional university environment they value. In light of the preoccupation of universities in coexisting with the new situation, they are putting most of their efforts into academic aspects while neglecting cultural and social aspects. In other words, they are focused on learning rather than on the learners [15]. Alleviating the burden of missing the traditional university environment should be a joint effort among the university, college, and faculty members. Universities should be creative and innovative in launching virtual activities. Furthermore, colleges can create community discussion boards for their students to share what is happening in their lives. Faculty members can contribute by encouraging their students to engage in activities and discussion boards.

Another challenge was the availability of digital devices. This issue is not a new challenge in online learning. Previous research on online learning has also highlighted the importance of resource availability, such as computers and reliable Internet connectivity $[35,55]$. Furthermore, a new challenge that was recognized is quarantine, which hindered students from using university facilities. In this study, some students who did not have access to computers at home or shared their devices with other family members struggled to participate in online learning. Universities should take steps to overcome this obstacle by either loaning or providing digital devices to students in need. They can also collaborate with service providers and those in the private sector to establish partnerships that can assist students during this crisis by providing free or at least low-cost services, highspeed Internet connectivity, devices, and other resources.

Several other components were raised as challenging for online learning due to quarantine and restrictions on the movement of students. Lack of access to external learning resources is a new issue raised by learners and is reported as a new challenge in the literature. To complete the learning process ideally, some students need to go to the library to perform their assignments and projects, go to the stores to buy equipment, or go to field training locations to complete their training. Some universities suspended or postponed the semester to ensure an optimal education process, while others preferred to continue and move fully to virtual education. In spite of this period being an uncertain time, universities should continuously strive to deliver highquality teaching and consistent support to students [56]. This study emphasizes the need for universities to think outside the box and search for feasible alternatives to teach optimally in crisis situations.

\section{Conclusion and Future Research}

Our findings support the notion that the current COVID-19 pandemic presented significant challenges and difficulties for undergraduate women. The current pandemic may further exacerbate already existing problems. The timeline of the pandemic is uncertain, further impacting undergraduate women's educational achievement, lives, and mental health. The results of this research revealed eight main challenges facing undergraduate women during the pandemic outbreak. Some challenges were associated with online learning in the literature, but their impact increased with the full transition and quarantine, namely, technical issues, limited availability of digital devices, distractions and time management, stress and psychological pressure, and lack of inperson interaction. Other challenges as missing traditional university environment, lack of systematic schedule, and lack of access to external learning resources have been emerged due to quarantine. Further research is recommended to replicate the current research on a larger sample in different educational settings. Another study on undergraduate men is also advised to compare the effects of COVID-19 on graduate students of both genders. Additional studies investigating the challenges facing faculty members may provide a better understanding of the impact of COVID-19 on higher education. Further studies examining the effect of using distance education during COVID-19 crisis on learners' achievement motivation are also highly recommended. Finally, this study emphasizes that universities should balance between delivering high-quality teaching and providing consistent support to undergraduate women in crisis situations.

\section{Data Availability}

The survey results data used to support the findings of this study may be released upon application to the PNU Review Board/Deanship of Scientific Research/Princess Nourah bint Abdulrahman University, who can be contacted at irb@ pnu.edu.sa.

\section{Conflicts of Interest}

The author declares that there are no conflicts of interest.

\section{Acknowledgments}

This research was funded by the Deanship of Scientific Research at Princess Nourah bint Abdulrahman University through the Fast-Track Research Funding Program.

\section{References}

[1] M. Chahrour, S. Assi, M. Bejjani et al., "A bibliometric analysis of COVID-19 research activity: a call for increased output," Cureus, vol. 12, no. 3, 2020.

[2] Y.-T. Xiang, Y. Yang, W. Li et al., "Timely mental health care for the 2019 novel coronavirus outbreak is urgently needed," The Lancet Psychiatry, vol. 7, no. 3, pp. 228-229, 2020. 
[3] S. Spina, F. Marrazzo, M. Migliari, R. Stucchi, A. Sforza, and R. Fumagalli, “The response of Milan's emergency medical system to the COVID-19 outbreak in Italy," The Lancet, vol. 395, no. 10227, pp. e49-e50, 2020.

[4] J. Bedford, D. Enria, J. Giesecke et al., "COVID-19: towards controlling of a pandemic," The Lancet Journal, vol. 395, no. 10229, pp. 1015-1018, 2020.

[5] P. Sahu, "Closure of universities due to coronavirus disease 2019 (COVID-19): impact on education and mental health of students and academic staff," Cureus, vol. 12, no. 4, 2020.

[6] IESALK, COVID-19 and Higher Education: Today and Tomorrow, UNESCO, Paris, France, 2020.

[7] B. Orser, A. Riding, and J. Stanley, "Perceived career challenges and response strategies of women in the advanced technology sector," Entrepreneurship \& Regional Development, vol. 24, no. 1-2, pp. 73-93, 2012.

[8] C. Ward-Griffin, J. B. Brown, A. Vandervoort, S. McNair, and I. Dashnay, "Double-duty caregiving: women in the health professions," Canadian Journal on Aging/La Revue canadienne du vieillissement, vol. 24, no. 4, pp. 379-394, 2005.

[9] B. P. Gabster, K. v. Daalen, R. Dhatt, and M. Barry, "Challenges for the female academic during the COVID-19 pandemic," The Lancet, vol. 395, no. 10242, pp. 1968-1970, 2020.

[10] R. M. Viner, S. J. Russell, H. Croker et al., "School closure and management practices during coronavirus outbreaks including COVID-19: a rapid systematic review," The Lancet Child \& Adolescent Health, vol. 4, no. 5, pp. 397-404, 2020.

[11] A. Gupta and M. Goplani, "Impact of COVID-19 on educational institutions in India," Purakala (UGC CARE Journal), vol. 31, no. 21, pp. 661-671, 2020.

[12] B. Williamson, R. Eynon, and J. Potter, "Pandemic politics, pedagogies and practices: digital technologies and distance education during the coronavirus emergency," Learning, Media and Technology, vol. 45, no. 2, pp. 107-114, 2020.

[13] M. B. N. Wajdi, I. Kuswandi, U. A. Faruq, Z. Zulhijra, K. Khairudin, and K. Khoiriyah, "Education policy overcome coronavirus, a study of Indonesians," EDUTEC: Journal of Education And Technology, vol. 3, no. 2, pp. 96-106, 2020.

[14] S. Affouneh, S. Salha, and Z. N. Khlaif, "Designing quality E-learning environments for emergency remote teaching in coronavirus crisis," Interdisciplinary Journal of Virtual Learning in Medical Sciences, vol. 11, no. 2, pp. 1-3, 2020.

[15] A. Bozkurt and R. C. Sharma, "Emergency remote teaching in a time of global crisis due to CoronaVirus," Asian Journal of Distance Education, vol. 15, no. 1, 2020.

[16] J. Crawford, K. Butler-Henderson, J. Rudolph, and M. Glowatz, "COVID-19: 20 countries' higher education intra-period digital pedagogy responses," Journal of Applied Teaching and Learning (JALT), vol. 3, no. 1, 2020.

[17] X. Zhang, "Thoughts on large-scale long-distance web-based teaching in colleges and universities under novel coronavirus pneumonia epidemic: a case of Chengdu university," in Proceedings of the 4th International Conference on Culture, Education and Economic Development of Modern Society (ICCESE 2020), pp. 1222-1225, Atlantis Press, Moscow, Russia, April 2020.

[18] A. Al-Rabiaah, M.-H. Temsah, A. A. Al-Eyadh et al., "Middle East respiratory syndrome-corona virus (MERS-CoV) associated stress among medical students at a university teaching hospital in Saudi Arabia," Journal of Infection and Public Health, vol. 13, no. 5, 2020.

[19] L. Rababah, "ICT obstacles and challenges faced by English language learners during the coronavirus outbreak in Jordan,"
International Journal of Linguistics, vol. 12, no. 3, pp. 28-36, 2020.

[20] R. A. Moawad, "Online learning during the COVID-19 pandemic and academic stress in university students," Revista Românească Pentru Educaţie Multidimensională, vol. 12, no. 1, pp. 100-107, 2020.

[21] A. Bozkurt, I. Jung, J. Xiao et al., "A global outlook to the interruption of education due to COVID-19 pandemic: navigating in a time of uncertainty and crisis," Asian Journal of Distance Education, vol. 15, no. 1, pp. 1-126, 2020.

[22] Al-Balad, "Integrated system of distance education at Princess Nourah Bint Abdul Rahman University," 2020.

[23] 2020 D. o. e-learning, writer, learning management system indicators. [Performance]. Princess Nourah Bint Abdulrahman University (PNU).

[24] P. D. Leedy, Practical Research, Planning and Design, Pearson Education Inc., London, UK, 3rd edition, 2005.

[25] J. W. Creswell and J. D. Creswell, Research Design; Qualitative, Quantitative and Mixed Method Approaches, Sage Publication, Thousand Oaks, CA, 2017.

[26] J. Omona, "Sampling in qualitative research: improving the quality of research outcomes in higher education," Makerere Journal of Higher Education, vol. 4, no. 2, pp. 169-185, 2013.

[27] M. B. Miles and A. M. Huberman, Qualitative Data Analysis: An Expanded Sourcebook, Sage, Thousand Oaks, CA, USA, 2nd edition, 1994.

[28] P. I. Fusch and L. R. Ness, "Are we there yet? Data saturation in qualitative research," The Qualitative Report, vol. 20, no. 5, p. $1408,2015$.

[29] J. Rabiega-Wiśniewska, "When students faced online learning in coronavirus times. A case study," in Proceedings of the 2020 International Virtual Conference on Education, Teaching and Learning-IVCETL 2020, Vilnius, Lithuania, May 2020.

[30] L. R. Kearns, "Student assessment in online learning: challenges and effective practices," MERLOT Journal of Online Learning and Teaching, vol. 3, 2012.

[31] R. Van de Vord and K. Pogue, "Teaching time investment: does online really take more time than face-to-face?" The International Review of Research in Open and Distributed Learning, vol. 13, no. 3, pp. 132-146, 2010.

[32] G. Stankovska, I. Memedi, and D. Dimtrovski, "Coronavirus COVID-19 disease, mental health and psychosocial support," Society Register, vol. 4, no. 2, pp. 33-48, 2020.

[33] G. Basilaia and D. Kvavadze, "Transition to online education in schools during a SARS-COVID-19 coronavirus (COVID19) pandemic in Georgia," Pedagogical Research, vol. 5, no. 4, pp. 1-9, 2020.

[34] J. L. Moore, C. Dickson-Deane, and K. Galyen, "e-learning, online learning, and distance learning environments: are they the same?" The Internet and Higher Education, vol. 14, no. 2, pp. 129-135, 2011.

[35] L. Song, E. S. Singleton, J. R. Hill, and M. H. Koh, "Improving online learning: student perceptions of useful and challenging characteristics," The Internet and Higher Education, vol. 7, no. 1, pp. 59-70, 2004.

[36] F. Ollermann, R. Rolf, C. Greweling, and A. Klaßen, "Principles of successful implementation of lecture recordings in higher education," Interactive Technology and Smart Education, vol. 14, no. 1, 2017.

[37] M. Tzifopoulos, "In The shadow of Coronavirus: distance education and digital literacy skills in Greece," International Journal of Social Science and Technology, vol. 5, no. 2, pp. 1-14, 2020. 
[38] J. R. Hill, "Overcoming obstacles and creating connections: community building in web-based learning environments," Journal of Computing in Higher Education, vol. 14, no. 1, p. 67, 2002.

[39] A. L. Gonzales, J. M. Calarco, and T. Lynch, "Technology problems and student achievement gaps: a validation and extension of the technology maintenance construct," Communication Research, vol. 47, no. 5, pp. 750-770, 2020.

[40] K. Carey, Everybody Ready for the Big Migration to Online College? Actually, No, https://www.nytimes.com/2020/03/13/ upshot/coronavirus-online-college-classes-unprepared.html, The New York Times, New York, NY, USA, 2020, https:// www.nytimes.com/2020/03/13/upshot/coronavirus-onlinecollege-classes-unprepared.html.

[41] A. Al-Rasheed and J. Berri, "Effective reuse and sharing of best teaching practices," Computer Applications in Engineering Education, vol. 25, no. 2, pp. 163-178, 2017.

[42] F. Almutairi and S. White, "How to measure student engagement in the context of blended-MOOC," Interactive Technology and Smart Education, vol. 15, no. 3, 2018.

[43] G. O. Mellow, D. D. Woolis, M. Klages-Bombich, and S. Restler, Taking College Teaching Seriously: Pedagogy Matters!, LLC: Stylus Publishing, Sterling, VA, USA, 2015.

[44] M. K. Wilhelm-Chapin and T. A. Koszalka, "Graduate students' use and perceived value of learning resources in learning the content in an online course," TechTrends, vol. 64, no. 3, pp. 361-372, 2020.

[45] D. Xu and S. Jaggars, "Adaptability to online learning: differences across types of students and academic subject areas," Journal of Higher Education, vol. 45, 2013.

[46] A. Al-Rasheed and J. Berri, "Engineering domain expertise through best practices management: application to the field of education," in Proceedings of the 2016 7th International Conference on Information and Communication Systems (ICICS), pp. 133-138, IEEE, Irbid, Jordan, April 2016.

[47] L. Dyrbye, A. Cumyn, H. Day, and M. Heflin, "A qualitative study of physicians' experiences with online learning in a masters degree program: benefits, challenges, and proposed solutions," Medical Teacher, vol. 31, no. 2, pp. 40-46, 2009.

[48] C. Hodges, S. Moore, B. Lockee, T. Trust, and A. Bond, "The difference between emergency remote teaching and online learning," Educause Review, vol. 27, 2020.

[49] N. Doghonadze, A. Aliyev, H. Halawachy et al., "The degree of readiness to total distance learning in the face of COVID-19teachers (case of Azerbaijan, Georgia, Iraq, Nigeria, UK and Ukraine)," Journal of Education in Black Sea Region, vol. 5, no. 2, 2020.

[50] M. Sarner, "Maintaining mental health in the time of coronavirus," New Scientist, vol. 246, no. 3279, pp. 40-46, 2020.

[51] N. Noddings, Starting at Home: Caring and Social Policy, University of California Press, Berkeley, CA, USA, 2002.

[52] J. Zimmerman, Coronavirus and the Great Online-Learning Experiment, The Chronicle of Higher Education, Washington, D. C., USA, 2020, https://www.chronicle.com/article/ Coronavirusthe-Great/248216.

[53] A. Al-Rasheed, "Knowledge management of best practices in a collaborative environment," International Journal of Advanced Computer Science and Applications (IJACSA), vol. 7, no. 3, 2016.

[54] Y. Zheng, J. Li, M. Zhang et al., "A survey of the psychological status of primary school students who were quarantined at home during the coronavirus disease 2019 epidemic in Hangzhou China," MedRxiv, 2020.
[55] L. Rababah, N. Bani-Melhem, M. Jdaitawi, B. Rababah, and O. Rababah, "EFL teachers' barriers to the use of ICT in instruction in Jordan," in Proceedings of the 1st International Conference on Behavioural and Social Science Research (ICBSSR), Kampar, Malaysia, November 2012.

[56] H. Fabrice, Learning Our Lesson Review of Quality Teaching in Higher Education: Review of Quality Teaching in Higher Education, OECD Publishing, Paris, France, 2010. 